\title{
Глава 8.
}

\section{АГРОХИМИЯ И ПОЧВОВЕДЕНИЕ}

\section{РАЗРАБОТКА НАУЧНЫХ ОСНОВ ПРИМЕНЕНИЯ УДОБРЕНИЙ В ИНТЕНСИВНОМ САДОВОДСТВЕ СРЕДНЕЙ ЗОНЫ РОССИИ}

Трунов Ю. В.

\author{
Федеральное государственное бюджетное \\ образовательное учреждение выстего образования \\ «Мичуринский государственный аграрный университет», \\ 2. Мичуринск, Россия, e-mail: trunov.yu58@mail.ru
}

Разработаны технологические регламенты для средней полосы России: применения корневых и некорневых минеральных подкормок для интенсивного маточника и питомника яблони, позволяющий увеличить выход стандартных саженцев и подвоев на 15-20 \%; применения макро- и микроэлементов в промышленном саду яблони в условиях воздействия комплекса экологических факторов, обеспечивающий повышение рентабельности возделывания на 15-20\%. Усовершенствована технология минерального питания яблони в средней полосе России на базе применения минеральных удобрений в виде основного внесения, почвенных и некорневых подкормок и фертигации, позволяющая оптимизировать ростовые процессы растений, повысить потенциал его адаптивности к абиотическим и биотическим стрессорам, урожайность и качество плодов яблони. В опытах достигнуто повышение уровня рентабельности производства плодов на $22 \ldots 34 \%$.

Ключевые слова: яблоня, интенсивный сад, питомник, минеральное питание, удобрение, некорневые подкормки, фертигация.

Удобрение является важнейшим приёмом регулирования роста и плодоношения плодовых деревьев, повышения урожайности и качества плодов [35].

В области минерального питания растений разработаны теоретические основы минерального питания растений:

- показана роль экологических факторов в процессе минерального питания плодовых и ягодных растений $[4,6,9,15,16,18,19,22,23,31]$;

- создана концепция удобрения плодовых и ягодных растений с учётом антагонистических и синергетических взаимосвязей между ионами минеральных веществ при их поглощении корнями [15]; 
- установлена генотипическая специфика минерального питания плодовых и ягодных растений при различных уровнях экологических факторов [18].

В разных почвенно-климатических зонах установлена эффективность использования удобрений в садоводстве при их рациональном и правильном применении:

- для традиционных типов насаждений разработаны средние дозы, сроки и способы внесения удобрений по основным плодовым и ягодным культурам [2, 5, 15, 16, 17, 23, 29, 30, 34, 40, 41];

- показана роль отдельных элементов минерального питания в жизнедеятельности плодовых и ягодных культур азота, фосфора, калия, кальция, некоторых микроэлементов на различных этапах онтогенеза растений [1, 13-15, 27, 31, 37];

- разработаны конструкции машин для поверхностного и глубокого внесения удобрений в садоводстве.

Установлена эффективность некорневых подкормок плодовых и ягодных растений макро-и микроэлементами в разных почвенно-климатических зонах:

- показана роль отдельных минеральных элементов в формировании компонентов продуктивности и устойчивости растений в процессе онтогенеза $[7,11,28,36]$;

- предложены комплексы некорневых обработок плодовых растений по фенологическим фазам развития, определены диапазоны концентраций препаратов.

Разработаны методики установления и корректировки доз минеральных удобрений:

- разработана и широко используется методика корректировки средних зональных доз удобрений на основе результатов почвенных анализов и растительной (листовой) диагностики минерального питания [8, $15,20,33,34,37,38]$;

- предложена методика оптимизации содержания элементов питания в почве путём доведения их концентрации до среднеобеспеченного или оптимального уровней [22];

- предложена методика определения потребности многолетних насаждений в удобрении по выносу основных элементов питания с биомассой и урожаем с учётом потерь (балансовый метод) [3, 8, 12, 32, 35, 37, 39].

А. К. Кондаковым (2007) в Мичуринске создана концепция удобрения плодовых растений с учётом антагонистических и синергетических взаимосвязей между различными ионами минеральных веществ при их поглощении корнями [15]. 
Глава 8. Агрохимия и почвоведение

Объекты и методы. Исследования проводили в 1985-2019 гг. в условиях ЦФО РФ. Объектами служили клоновые подвои яблони, привитые на них сорта, интенсивные сады с различной плотностью посадки, различные типы чернозёмных почв. Исследования проводили в соответствии с Программой и методикой сортоизучения плодовых, ягодных и орехоплодных культур (Мичуринск, 1973; Орёл, 1999), Программно-методическими указаниями по агротехническим опытам с плодовыми и ягодными культурами (Мичуринск, 1956), Методикой полевого опыта (1979) [10, 24-26].

Результаты и их обсуждение. В наших 35-летних опытах по изучению минерального питания яблони в средней полосе России получены следующие результаты:

\section{1. Принципы расчета средних доз удобрений}

Наиболее распространёнными методами расчета доз удобрений являются:

- метод корректировки рекомендуемой дозы по результатам анализа почвы и растений с использованием поправочных коэффициентов;

- метод корректировки рекомендуемой дозы по выносу элементов с биомассой и урожаем с использованием поправочных коэффициентов [35].

Принцип внесения удобрений при подготовке почвы - доведение содержания минеральных доступных элементов до среднего или высокого уровня.

Чтобы повысить содержание в почве (в слое 0-50 см) любого минерального элемента на 10 мг/кг почвы, нужно внести в почву соответствующее минеральное удобрение в норме 50 кг действующего вещества на 1 га

- внесение аммиачной селитры (33-35 \% д. в.) - 150 кг/га;

- внесение двойного суперфосфата (45 \% д. в.) - 110 кг/га;

- внесение калийной соли (40 \% д. в.) - 120 кг/га

Окончательная величина дозы минеральных удобрений, максимально оптимизирующая для растений концентрацию почвенного раствора и обеспечивающая потребление минеральных элементов из почвы на построение вегетативной биомассы и урожая, состоит из двух слагаемых:

где,

$$
\text { Д = Допт. }+ \text { Дкорр. }
$$

Допт. - доза, повышающая концентрацию элементов в почве до оптимальных значений;

Дкорр. - доза, обеспечивающая вынос (потребление) элементов биомассой и урожаем.

Доза удобрений, рассчитанная на основе повышения содержания элемента в почве до её благоприятного значения для яблони, может быть получена по формуле: 
гेe,

$$
\text { Допт. }=(\text { Сср. }- \text { Сфакт. }) \times \text { Км }
$$

Допт. = доза удобрений, оптимизирующая содержание минерального элемента в почве, кг/га;

Cср. = средняя (минимальная эффективная) концентрация минерального элемента в почве, мг/кг;

Сфакт. = фактическая концентрация минерального элемента в почве, мг/кг;

Км = массовый коэффициент удобренного слоя почвы;

где,

$$
\mathrm{KM}=\mathrm{pSh}=5
$$

плотность почвы $\mathrm{p}=1,25$ г/ $\mathrm{cm}^{3}$;

площадь участка $\mathrm{S}=1$ га;

толщина слоя почвы $\mathrm{h}=40 \mathrm{~cm}$.

Рассчитывать корректирующую дозу удобрений необходимо с учётом основных поправочных коэффициентов (К), которая должна компенсировать вынос минерального элемента из почвы с биомассой и урожаем.

Доза удобрений, корректирующая вынос минерального элемента растениями, рассчитывают по формуле:

где,

$$
\text { Дкорр. }=\text { Дср. }(1+\mathrm{Kn})
$$

Дкорр. = корректирующая доза удобрений, кг/га;

Дср. = средняя рекомендуемая зональная доза удобрений, кг/га;

Кn = поправочные коэффициенты к средней дозе удобрений по наиболее значимым факторам

$\mathrm{K}_{1}$ - поправочный коэффициент по степени интенсивности сада и плановой урожайности для азота, фосфора и калия;

$\mathrm{K}_{2}$ - поправочный коэффициент для азота по способу содержания почвы в саду;

$\mathrm{K}_{3}$ - поправочный коэффициент для азота по степени обрезки деревьев;

$\mathrm{K}_{2}$ и $\mathrm{K}_{3}$ для фосфорных и калийных удобрений принимаются равными 0.

\section{2. Корректировка средних доз удобрений}

В средней зоне садоводства России яблоня, прежде всего, нуждается: в молодом саду - в азотных удобрениях, в плодоносящем саду - в азотных и калийных удобрениях.

Нами предложены поправочные коэффициенты к средней дозе удобрений (табл. 1-5). 


\section{Таблица 1}

Поправочные коэффициенты к средней дозе азотных удобрений по степени интенсивности сада и плановой урожайности $\left(K_{1}\right)$

\begin{tabular}{|c|c|c|c|c|}
\hline \multirow{2}{*}{$\begin{array}{c}\text { Урожайность } \\
m / 2 a\end{array}$} & \multicolumn{4}{|c|}{ Тип сада (кол-во деревьев на 1 га, mыс. шт.) } \\
\cline { 2 - 5 } & $300-500$ & $600-1200$ & $1500-3500$ & $>3500$ \\
\hline 0 & 0 & $+0,05$ & $+0,10$ & $+0,15$ \\
\hline $5-10$ & 0 & $+0,10$ & $+0,15$ & $+0,20$ \\
\hline $10-20$ & $+0,10$ & $+0,15$ & $+0,20$ & $+0,25$ \\
\hline $20-30$ & $+0,15$ & $+0,20$ & $+0,25$ & $+0,30$ \\
\hline $30-40$ & $+0,20$ & $+0,25$ & $+0,30$ & $+0,35$ \\
\hline $40-60$ & & $+0,30$ & $+0,35$ & $+0,40$ \\
\hline
\end{tabular}

Поправочные коэффициенты

Таблийа 2

к средней дозе азотных удобрений по способу содержания почвы в междурядьях и приствольной полосе $\left(K_{2}\right)$

\begin{tabular}{|c|c|c|c|}
\hline \multirow{2}{*}{$\begin{array}{c}\text { Способ } \\
\text { содержания почвы }\end{array}$} & \multicolumn{3}{|c|}{ Возраст сада } \\
\hline & 1-3 года & 4-6 лет & Более 6 лет \\
\hline Гербицидный пар & $-0,15$ & $-0,10$ & 0,05 \\
\hline Мульчирование & $-0,15$ & $-0,10$ & $-0,05$ \\
\hline Чёрный пар & 0 & 0 & 0 \\
\hline Залужение & $+0,50$ & $+0,25$ & $+0,10$ \\
\hline
\end{tabular}

Таблица 3

Поправочные коэффициенты к средней дозе азотных удобрений по степени обрезки $\left(K_{3}\right)$

\begin{tabular}{|l|c|c|c|}
\hline \multirow{2}{*}{ Степень обрезки } & \multicolumn{3}{|c|}{ Возраст сада } \\
\cline { 2 - 4 } & $1-3$ года & $1-3$ года & $1-3$ года \\
\hline Без обрезки & 0 & 0 & 0 \\
\hline Слабая обрезка & 0 & $-0,10$ & $-0,10$ \\
\hline Средняя обрезка & 0 & $-0,20$ & $-0,25$ \\
\hline Сильная обрезка & 0 & $-0,30$ & $-0,50$ \\
\hline
\end{tabular}


Поправочные коэффициенты к средней дозе калийных удобрений по степени интенсивности сада и плановой урожайности $\left(K_{1}\right)$

\begin{tabular}{|c|c|c|c|c|}
\hline \multirow{2}{*}{$\begin{array}{c}\text { Урожайность } \\
m / 2 a\end{array}$} & \multicolumn{4}{|c|}{ Тип сада (количество деревьев на 1 га, тыс. шт.) } \\
\cline { 2 - 5 } & $\begin{array}{c}\text { сильно- } \\
\text { рослый } \\
300-500\end{array}$ & $\begin{array}{c}\text { средне- } \\
\text { рослый } \\
600-1200\end{array}$ & $\begin{array}{c}\text { интен- } \\
\text { сивный } \\
1500-3500\end{array}$ & $\begin{array}{c}\text { супер- } \\
\text { интенсивный } \\
>3500\end{array}$ \\
\hline 0 & $-0,25$ & 0 & $-0,15$ & 0,10 \\
\hline $5-10$ & 0 & 0 & 0,10 & 0,20 \\
\hline $10-20$ & 0,10 & 0,20 & 0,30 & 0,40 \\
\hline $20-30$ & 0,20 & 0,30 & 0,50 & 0,60 \\
\hline $30-40$ & 0,30 & 0,50 & 0,70 & 0,80 \\
\hline $40-60$ & 0,40 & 0,60 & 0,80 & 1,00 \\
\hline
\end{tabular}

Таблица 5

Поправочные коэффициенты к средней дозе фосфорных удобрений по степени интенсивности сада и плановой урожайности $\left(K_{1}\right)$

\begin{tabular}{|c|c|c|c|c|}
\hline \multirow{2}{*}{$\begin{array}{c}\text { Урожайность } \\
m / 2 a\end{array}$} & \multicolumn{4}{|c|}{ Тип сада (количество деревьев на 1 га, тыс. шт.) } \\
\cline { 2 - 5 } & $\begin{array}{c}\text { сильнорос- } \\
\text { лый } \\
300-500\end{array}$ & $\begin{array}{c}\text { средне- } \\
\text { рослый } \\
600-1200\end{array}$ & $\begin{array}{c}\text { интен- } \\
\text { сивный } \\
1500-3500\end{array}$ & $\begin{array}{c}\text { супер- } \\
\text { интенсивный } \\
>3500\end{array}$ \\
\hline 0 & $-0,25$ & $-0,20$ & $-0,15$ & $-0,10$ \\
\hline $5-10$ & 0 & 0 & 0,10 & 0,15 \\
\hline $10-20$ & 0,05 & 0,10 & 0,15 & 0,20 \\
\hline $20-30$ & 0,10 & 0,15 & 0,20 & 0,25 \\
\hline $30-40$ & 0,15 & 0,20 & 0,25 & 0,30 \\
\hline
\end{tabular}

\section{3. Системы удобрений в насаждениях яблони.}

Разработана система основного внесения удобрений в насаждениях яблони в средней зоне садоводства России (табл. 6-9). 
Глава 8. Агрохимия и почвоведение

\section{Таблица 6}

Система удобрения

интенсивных среднерослых яблоневых садов, средние дозы

\begin{tabular}{|l|c|c|c|}
\hline \multirow{2}{*}{\multicolumn{1}{|c|}{ Сроки и способы внесения }} & \multicolumn{3}{|c|}{ Дозы удобрений, кг/га д.в. } \\
\cline { 2 - 4 } & $\mathrm{N}$ & $\mathrm{P}_{2} \mathrm{O}_{5}$ & $\mathrm{~K}_{2} \mathrm{O}$ \\
\hline $\begin{array}{l}\text { До посадки под вспашку на глубину } \\
20-25 \text { см, при дозе навоза 60 m/2a }\end{array}$ & 90 & 30 & 120 \\
\hline $\begin{array}{l}\text { Молодой сад, под кроны на глубину } \\
10-15 \text { см, 1 раз в 2-3 года }\end{array}$ & $60-90$ & 30 & $30-60$ \\
\hline $\begin{array}{l}\text { Плодоносящий сад, междурядья } \\
\text { На глубину 15-25 см, 1 раз в 2 года }\end{array}$ & $90-120$ & $30-60$ & $120-180$ \\
\hline
\end{tabular}

\section{Система удобрения}

Таблииа 7

интенсивных карликовых яб̆лоневых садов, средние дозы

\begin{tabular}{|c|c|c|c|}
\hline \multirow{2}{*}{ Сроки и способы внесения } & \multicolumn{3}{|c|}{ Дозы удобрений, кг/га д.в. } \\
\cline { 2 - 4 } & $\mathrm{N}$ & $\mathrm{P}_{2} \mathrm{O}_{5}$ & $\mathrm{~K}_{2} \mathrm{O}$ \\
\hline $\begin{array}{c}\text { До посадки под вспашку на глубину } \\
\text { 20-25 см, при дозе навоза 60 т/га }\end{array}$ & 90 & 30 & 120 \\
\hline $\begin{array}{c}\text { Молодой сад, под кроны } \\
\text { На глубину 10-15 см, 1 раз в 2-3 года }\end{array}$ & $90-120$ & $30-45$ & $60-90$ \\
\hline $\begin{array}{c}\text { Плодоносящий сад, под кроны } \\
\text { На глубину 15-25 см, 1 ра3 в 2 года }\end{array}$ & $120-150$ & $60-90$ & $150-240$ \\
\hline
\end{tabular}

\section{Система удобрения}

Таблица 8

питомника семечковых культур, средние дозы

\begin{tabular}{|l|c|c|}
\hline \multicolumn{2}{|c|}{ Способы и сроки внесения } & Дозы удобрений \\
\hline До посадки, под вспашку & Осенью & $\begin{array}{c}\text { Навоз до } 80 \text { т/га } \\
\text { Или } \mathrm{N}_{90} \mathrm{P}_{30} \mathrm{~K}_{120}\end{array}$ \\
\hline Первое поле & весной & $\mathrm{N}_{60}$ \\
\hline Второе поле & весной & $\mathrm{N}_{30} \mathrm{P}_{30} \mathrm{~K}_{30-45}$ \\
\hline Третье поле & весной & не вносить \\
\hline
\end{tabular}


Система удобрения

маточника клоновых подвоев яблони, средние дозь

\begin{tabular}{|c|c|c|}
\hline \multicolumn{2}{|c|}{ Способы и сроки внесения } & Дозы удобрений \\
\hline До посадки, под вспашку & Осенью & Навоз до 80 т/га \\
\hline Первый год после посадки & весной & $\mathrm{N}_{60}$ \\
\hline $1-5$ годы эксплуатации & весной & $\mathrm{N}_{90} \mathrm{~K}_{30-60}$ \\
\hline 6-10 годы эксплуатации & весной & $\mathrm{N}_{120} \mathrm{P}_{30-45} \mathrm{~K}_{60-90}$ \\
\hline
\end{tabular}

Разработана система некорневых подкормок удобрениями интенсивного яблоневого сада в средней зоне садоводства России (табл. 10-11).

Таблица 10

\section{Примерная система \\ некорневых подкормок яблони удобрениями \\ в молодом саду}

\begin{tabular}{|c|c|c|c|c|}
\hline Объекты & $\begin{array}{c}\text { Фенофазы } \\
\text { развития растений }\end{array}$ & Сроки & Элементы & $\begin{array}{c}\text { Концен- } \\
\text { трация, } \\
\%\end{array}$ \\
\hline \multirow{5}{*}{ 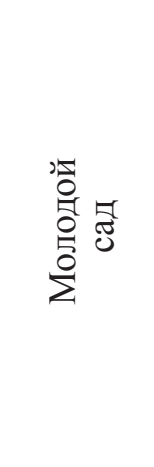 } & Распускание листьев & $\begin{array}{c}\text { начало } \\
\text { мая }\end{array}$ & NPK & 0,5 \\
\hline & Начало роста побегов & $\begin{array}{c}\text { середина } \\
\text { мая }\end{array}$ & NPK & 0,5 \\
\hline & Интенсивный рост побегов & $\begin{array}{c}\text { начало } \\
\text { июня }\end{array}$ & NPK & 0,5 \\
\hline & Интенсивный рост побегов & $\begin{array}{c}\text { конец } \\
\text { июня }\end{array}$ & NPK & 0,5 \\
\hline & Рост побегов & $\begin{array}{c}\text { середина } \\
\text { июля }\end{array}$ & NPK & 0,5 \\
\hline
\end{tabular}

Предложена примерная годовая норма удобрений для фертигации в интенсивных садах яблони:

- молодой сад $\mathrm{N}_{15-20} \mathrm{P}_{5-10} \mathrm{~K}_{10-15}$;

- плодоносящий сад $\mathrm{N}_{25-30} \mathrm{P}_{15-20} \mathrm{~K}_{25-30}$.

Заключение. Разработаны технологические регламенты для средней полосы России:

- применения корневых и некорневых минеральных подкормок для интенсивного маточника и питомника яблони, позволяющий увеличить выход стандартных саженцев и подвоев на 15-20 \%; 
Глава 8. Агрохимия и почвоведение

- применения макро- и микроэлементов в промышленном саду яблони в условиях воздействия комплекса экологических факторов, обеспечивающий повышение рентабельности возделывания на 15-20 \%.

Таблица 11

Примерная система

некорневых подкормок яблони удобрениями в плодоносящем саду

\begin{tabular}{|c|c|c|c|c|}
\hline \multirow{12}{*}{ 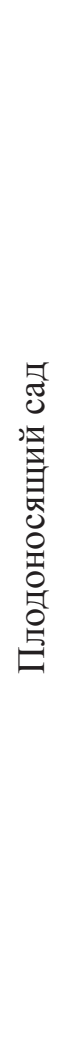 } & Спящие почки & Конец апреля & $\mathrm{Ca}$ & 0,08 \\
\hline & $\begin{array}{l}\text { Распускание } \\
\text { листьев }\end{array}$ & начало мая & $\begin{array}{c}\mathrm{NPK} \\
\mathrm{Mn}+\mathrm{Zn}\end{array}$ & $0,5+0,01+0,01$ \\
\hline & Розовый бутон & середина мая & $\mathrm{NPK}+\mathrm{B}$ & $0,5+0,02$ \\
\hline & Конец цветения & конец мая & $\mathrm{NPK}+\mathrm{B}+\mathrm{Ca}$ & $0,5+0,02+0,08$ \\
\hline & Опадение завязи & начало июня & NPK & 0,5 \\
\hline & Плод «лещина» & середина июня & NPK & 0,5 \\
\hline & $\begin{array}{l}\text { Плод } \\
\text { «грецкий орех» }\end{array}$ & конец июня & $\mathrm{NPK}+\mathrm{Ca}$ & $0,5+0,08$ \\
\hline & Рост плодов & начало июля & $\mathrm{NPK}+\mathrm{Ca}$ & $0,5+0,08$ \\
\hline & Рост плодов & середина июля & $\mathrm{Ca}$ & 0,08 \\
\hline & Рост плодов & конец июля & $\mathrm{Ca}$ & 0,08 \\
\hline & $\begin{array}{l}\text { Налив и созре- } \\
\text { вание плодов }\end{array}$ & начало августа & $\mathrm{Ca}$ & 0,08 \\
\hline & $\begin{array}{l}\text { Опадение } \\
\text { листьев }\end{array}$ & октябрь & мочевина & $1,0-2,0$ \\
\hline
\end{tabular}

Усовершенствована технология минерального питания яблони в средней полосе России на базе применения минеральных удобрений в виде основного внесения, почвенных и некорневых подкормок и фертигации, позволяющая оптимизировать ростовые процессы растений, повысить потенциал его адаптивности к абиотическим и биотическим стрессорам, урожайность и качество плодов яблони. В опытах достигнуто повышение уровня рентабельности производства плодов на $22 \ldots 34$ \%.

\section{Библиографический список}

1. Анспок П.И. Микроудобрения: справочник. - 2-е изд., перераб. и доп. - Л.: Агропромиздат. Ленингр. отд-ние, 1990. - 272 с. 
2. Антошин С.Г. Удобрение в плодоводстве. - М., Л., 1932. - 168 с.

3. Бабук В.И. Биологические и технологические основы повышения продуктивности насаждений яблони на клоновых подвоях // Слаборослые клоновые подвои в садоводстве: сб. науч. тр. - Мичуринск, 1997. - С. 7-8.

4. Болотов А.Т. Избранные труды / сост. Бердышев А.П., Поздняков В.Г. - М.: Агропромиздат, М., 1988. - 416 с. - ISBN 5-10-001552-7.

5. Будаговский В.И. Культура слаборослых плодовых деревьев. - М.: Колос, 1976. - 302 с. 6. Вахмистров Д.Б., Воронцов В.А. Соотношение элементов минерального питания в среде и рост растений. Исследование формы купола отклика // Физиология растений. - 1994. - T. 41. - № 1. - С. 56-63. - ISSN 0015-3303.

7. Гудковский В.А., Каширская Н.Я., Цуканова Е.М. Окислительный стресс плодовых и ягодных культур. - Тамбов: Изд. ТГТУ, 2001. - 88 с. - ISBN 5-8265-0135-9.

8. Девятов А.С. Повышение качества плодов деревьев и урожайности садов. - 2-е изд., перераб. и доп. - Минск, «Ураджай», 1985. - 215 с.

9. Докучаев В.В. Русский чернозём. - Санкт-Петербург:Типография Деклерона и Евдокимова, 1883. $-551 \mathrm{c}$.

10. Доспехов Б.А. Методика полевого опыта. - Изд. 4-е, перераб. и доп. - М.: Колос, 1979. - 416 с. - ISBN 978-5-458-23540-2.

11. Журбицкий 3.И. Физиологические и агрохимические основы применения удобрений. - М.: Изд-во акад. наук СССР, 1963. - 294 с.

12. Кашин В.И. Научные основы адаптивного садоводства. - М.: Колос, 1995. 335 c. - ISBN 5-10-003328-2.

13. Кобель Ф. Плодоводство на физиологической основе. - 2-е изд., пер. с нем. - М.: Сельхозгиз, 1957. - 376 с.

14. Колесников В.А. Корневая система плодовых и ягодных растений. - М.: Колос, 1974. - 509 с.

15. Кондаков А.К. Удобрение плодовых деревьев, ягодников, питомников и цветочных культур. - Мичуринск, БИС, 2007. - 254 с. - ISBN 978-5-98909-005-1.

16. Кондратьев К.Н. Экологические ресурсы продуктивности яблони в Поволжье. Саратов: Изд-во Саратовского университета, 1991. - 168 с.

17. Копытко, П.Г. Почвенно-агрохимические основы удобрений плодовых культур: автореф. дисс. ...д-ра с.-х. наук. - М.: ТСХА, 1986. - 27 с.

18. Лебедев В.М. Минеральное питание и биологическая продуктивность яблони: автореф. дисс. ... д-ра с.-х. наук. - Мичуринск, 1985. - 49 с.

19. Либих Ю. Химия в приложении к земледелию и физиологии. - М. - Л.: ОГИЗСельхозгиз, 1936.

20. Магницкий К.П. Методы определения потребности растений в удобрениях. - М.: Московский рабочий, 1972. - С. 23-42.

21. Потапов В.А. Влияние предпосадочной подготовки почвы на рост и плодоношение яблони // Агрохимия. - 1977. - № 4. - С. 78-83. - ISSN 0002-1881.

22. Митчерлих Э.А. Определение потребности почвы в удобрении. - М. -Л.: Издательство сельскохозяйственной и колхозно-кооперативной литературы. - 1931. -104 с.

23. Приймак А.К. Удобрения плодовых деревьев. - Краснодар, 1969. - 255 с.

24. Программа и методика сортоизучения плодовых, ягодных и орехоплодных культур / под ред. Г.А. Лобанова. - Мичуринск, 1973. - 492 с.

25. Программа и методика сортоизучения плодовых, ягодных и орехоплодных культур / под ред. Е.Н. Седова и Т.П. Огольцовой. - Орёл: ВНИИСПК, 1999. - 608 с. ISBN 5-900705-15-3. 
26. Программно-методические указания по агротехническим опытам с плодовыми и ягодными культурами / под ред. Н.Д. Спиваковского. - Мичуринск, 1956. - 184 с. 27. Прянишников Д.Н. Избранные сочинения. - Т. 1. - М.: Колос, 1965. - 634 с.

28. Пьяников В.Т. Внекорневое поглощение веществ плодовыми растениями: автореф. дисс... канд. с.-х. наук. - Мичуринск, 1972. - 18 с.

29. Рубин С.С., Попович П.Д. Применение удобрений в садах Украинской ССР. - Агрохимия. - 1981. - № 7. - С. 85-92. - ISSN 0002-1881.

30. Рындин С.Д. Удобрение садов и микроорганизмы почвы. - М.: Россельхозиздат, 1964. $-76 \mathrm{c}$.

31. Сабинин Д.А. Физиологические основы питания растений. - М.: Наука, 1955. - С. 285-388.

32. Садовски А. Удобрения садов, урожай и качество плодов // Тез. докл. науч.-практ. Межд. конф., Бобтай, 12-18 ноября 1990 г. - Вильнюс: 1990. - С. 14-16.

33. Семенюк Г.М. Диагностика минерального питания плодовых культур. - Кишинёв: «Штиинца», 1983. - 322 с.

34. Спиваковский Н.Д. Удобрение плодовых и ягодных культур. - М.: Россельхозиздат, 1984. - 270 c.

35. Трунов Ю.В. Биологические основы минерального питания яблони. - Мичуринск-наукоград РФ; Воронеж: Кварта, 2016. - 418 с. - ISBN 978-5-89609-430-2. 36. Урсуленко П.К. Физиологические основы агротехники ежегодного урожая и высокой морозоустойчивости яблони // Бюл. научно-технической информ. ВНИИС им. И.В. Мичурина. - Мичуринск, 1956. - С. 3-9.

37. Фидлер В. Листовой анализ в плодоводстве. - М.: Колос, 1970. - 94 с.

38. Церлинг В.В. Диагностика минерального питания сельскохозяйственных культур: справочник. - М.: Агропромиздат, 1990. - 235 с. - ISBN 5-10-000562-9.

39. Шорохов С.С., Руденко К.Н. Биологический вынос и отчуждение элементов питания молодыми деревьями яблони на разных фонах удобрений // Наука - производству: сб. науч. тр. - Тула: Приокское кн. изд-во, 1980. - Т. 10. - Ч. 2. - С. 74-79.

40. Ягодин Б.А., Смирнов П.М., Петербургский А.В. [и др.]. Агрохимия: учебник. М.: Агропромиздат, 1989. - 639 с. - ISBN 5-10-000624-2.

41. Язвицкий М.Н. Удобрение сада. - М.: Московский рабочий, 1972. - 256 с.

\title{
DEVELOPMENT OF THE SCIENTIFIC BASIS FOR FERTILIZERS APPLICATION IN INTENSIVE GARDENING OF CENTRAL RUSSIA
}

\author{
Trunov Yu. V. \\ Federal State Budgetary \\ Educational Institution of Higher Education \\ "Michurinsk State Agrarian University", \\ Michurinsk,Russia, e-mail: trunov.yu58@mail.ru
}

Process regulations were developed for central Russia in the following: use of root and foliar mineral top dressing for the intensive mother plant and nursery of the apple tree, which allows us to increase the yield of standard seedlings and stocks by 15-20 \%; use of macro- and micronutrients in the industrial garden of apple trees 
Субтропическое и декоративное садоводство (72)

under the influence of a set of environmental factors, which provides an increase in cultivation profitability by $15-20 \%$. The technology of mineral nutrition for apple trees in central Russia has been improved based on the use of mineral fertilizers in the form of main application, soil and foliar fertilizing and fertigation, helping to optimize plant growth processes and increase its adaptability to abiotic and biotic stressors, as well as yield and quality of apple fruits. In the experiments, an increase in the level of fruit production profitability was achieved by $22 \ldots 34 \%$.

Key words: apple tree, intensive garden, nursery, mineral nutrition, fertilizer, foliar feeding, fertigation. 